\title{
DIÁLOGOS COM \\ GUILLERMO O'DONNELL
}

Fábio Wanderley Reis

\section{RESUMO}

$\mathrm{O}$ artigo relembra a figura do cientista político argentino Guillermo O'Donnell (1936-2011) e reconsidera criticamente aspectos centrais de sua obra, particularmente sua tipologia de regimes autoritários modernos e suas análises da transição para e consolidação da democracia em países de experiência autoritária recente.

PALAVRAS-CHAVE: Guillermo O'Donnell; autoritarismo; democracia; transição.

\section{ABSTRACT}

An hommage in the form of a critical reflexion on Guillermo O'Donnell's (1936-2011) tipology of authoritarian regimes and his analysis of democratic transition and consolidation in countries of recent authoritarian experience.

KEYWORDS: Guillermo O'Donnell; authoritarian regimes; democracy; transition.

[1] Reis, Fábio W. e O’Donnell, Guillermo (orgs.). A democracia no Brasil: dilemas e perspectivas. São Paulo: Vértice, 1988.
Tive a felicidade de me aproximar de Guillermo O'Donnell e colaborar com ele durante algum tempo. A seu convite, passei o segundo semestre de 1983 comofellow do Helen Kellogg Institute for International Studies, então sob sua direção acadêmica, e colaboramos na organização de um simpósio internacional sob o título "Issues on Democracy and Democratization: North and South". Posteriormente, estive com ele, em 1986, como pesquisador visitante do Cebrap, onde organizamos juntos um volume coletivo ${ }^{1}$ e colaboramos, nos anos seguintes, em diferentes aspectos de projetos paralelos de pesquisa de opinião executados em São Paulo e Minas Gerais. Além da exposição prolongada ao vigor intelectual e à paixão com que era movido ao trabalho sobre os temas de autoritarismo e democracia que afetaram recentemente de modo tão duro os nossos países (pelos quais transitou alheio a fronteiras e lançou raízes múltiplas), destaco como pude ver esses traços se combinarem, em Guillermo O'Donnell, com a infalível afabilidade no trato. Pessoalmente, carregando a imagem difundida de polêmico e ranheta (da qual ele mesmo me advertia com bom humor), confesso-me amplamente devedor de sua cordialidade e gentileza. 
A marca principal de sua contribuição intelectual se associa, sem dúvida, ao exame dos regimes "burocrático-autoritários" (BA, como os chamou O'Donnell com frequência) na América do Sul da segunda metade do século $\mathrm{XX}$, realizado inicialmente em volume publicado em espanhol, em 1972, e em inglês, com forte impacto, no ano seguinte ${ }^{2}$. Enquadrados pelo panorama mundial da Guerra Fria e por mudanças socioeconômicas que incluíam industrialização, urbanização e mobilização política dos setores populares, com a ameaça, aos olhos do establishment, de subversão esquerdista, tais regimes surgem como reação, protagonizada pelos militares mas com o apoio ou a participação relevante ou decisiva de setores empresariais e de classe média, àquela ameaça e às turbulências ligadas a ela. O sentido "estrutural" de que assim se revestiam foi vinculado por O'Donnell aos desafios do "aprofundamento" do processo de industrialização, com a passagem da produção de bens de consumo à de bens intermediários e de capital e com as consequências em termos das composições e alianças de classe. Nela, o nacional-populismo de apelo multiclassista se via substituído pela dependência em relação a investimentos externos e aos interesses de corporações multinacionais, bem como pela ênfase correlata em políticas "ortodoxas" e a importância que adquirem seus porta-vozes "técnicos". Este último aspecto ajuda a justificar o adjetivo "burocrático" aplicado ao novo autoritarismo, junto com o fato importante de que os regimes BA se distinguiriam das ditaduras tradicionais por termos neles as corporações militares como tal a assumir o poder, em vez deste ou daquele general ou dos caudilhos tradicionais. ${ }^{3}$

Mas que dizer, por exemplo, do Chile pós-1973, com o protagonismo pessoal de Pinochet? E como relacionar os BA sul-americanos com a Espanha franquista e o Portugal de Salazar, para não falar do México do PRI? À parte a possível relevância, para uma tipologia de autoritarismos, da existência ou não de um chefe que personifica o regime ( $e$ suas relações não de todo claras com variáveis estruturais e a profissionalização das forças armadas), todos esses casos podem servistos, e o foram, como pertencendo a uma categoria intermediária entre a democracia representativa e o totalitarismo4. Se tomamos as análises de Salvador Giner e Gianfranco Pasquino no volume dedicado ao sul da Europa do livro Transições do regime autoritário, que O'Donnell organizou com Schmitter e Whiteheads, vemos que Giner apresenta o fascismo italiano como uma espécie de protótipo da categoria geral de "regimes ditatoriais mediterrâneos", enquanto Pasquino caracteriza o fascismo italiano como "experiência totalitária fracassada", o que sugere que o protótipo seria antes algo como o nazismo - e a conexão assim estabelecida entre diferentes autoritarismos torna problemática a pretensão de tratar cada um deles de maneira isolada ${ }^{6}$.
[2] O'Donnell, G. Modernización y Autoritarismo. Buenos Aires: Paidós, 1972; e Modernization and Bureaucratic Authoritarianism: Studies in South American Politics. Politics of Modernization Series. Berkeley: Institute of International Studies, University of California, 1973, n.9.

[3] Um útil volume referido ao autoritarismo burocrático-autoritário é Collier, David (org.).The NewAuthoritarianism in Latin America. Princeton, NJ: Princeton University Press, 1979. $O$ volume tem foco especial na contribuição de O'Donnell (vejam-se especialmente os capítulos inicial e final de D. Collier, "Overview of the Bureaucratic-Authoritarian Model" $e$ "The Bureaucratic-Authoritarian Model: Synthesis and Priorities for Future Research", bem como o capítulo de autoria do próprio $\mathrm{G}$. O'Donnell, “Tensions in the Bureaucratic-Authoritarian State and the Question of Democracy"). Há, porém, importante colaboração, às vezes crítica, de autores que se dedicaram autonomamente ao tema geral e influenciaram, em alguns casos, as ideias de O'Donnell.

[4] Não obstante a "peculiaridade" pretendida por Juan Linz para o autoritarismo de tipo espanhol, justamente opondo-se à ideia de que se trataria de uma categoria intermediária e, como tal, "instável”, que tenderia a evoluir numa direção ou noutra. Cf. Linz, Juan. "An Authoritarian Regime: Spain”. In: Rokkan, Stein e Allardt, Erik (orgs.). Mass Politics: Studies in Political Sociology. Nova York: Free Press, 1970.

[5] Giner, Salvador. "Economia política, legitimação e o Estado no sul da Europa". In: O’Donnell, G., Schmitter, Philippe C. e Whitehead, Lawrence (orgs.). Transições do regime autoritário: sul da Europa. São Paulo: Vértice, 1988, especialmente pp. 46-47; e Pasquino, Gianfranco. "A derrocada do primeiro regime fascista e a transição italiana para a democracia: 1943-1948". In: Ibidem, especialmente pp. 76-77.

[6] De grande interesse a respeito é Kurth, James R. "Industrial Change and Political Change: A European Perspective".In:Collier, op. cit., 1979. 
[7] Cardoso, Fernando Henrique. "On the Characterization of Authoritarian Regimes in Latin America". In: Collier, op. cit., 1979, pp. 37-38.

[8] Cf. O'Donnell, G. e Schmitter, P. Transições do regime autoritário: primeiras conclusões. São Paulo: Vértice, 1988, especialmente pp.18-19.

[9] Schmitter, Phillipe. "The Conceptual Travels of Transitologists and Consolidologists: How Far to the East Should They Attempt to Go?", com a colaboração de Terry Lynn Karl. Universidade de Stanford: manuscrito, dez. 1993 .

[10] Ver em particular O'Donnell, G. "Antecedentes teóricos e históricos para el estudio del Estado burocrático autoritario". In: 1966-1973: El Estado Burocrático Autoritário. Buenos Aires: Belgrano, 1982.
Isso introduz o que é provavelmente o principal problema metodológico e substantivo (ou teórico) com que depara o esforço de O'Donnell e cujo desafio lhe esteve sempre presente, embora se tenha posicionado de modos diversos diante dele em diferentes momentos. Em sua contribuição a The New Authoritarianism in Latin America, Fernando Henrique Cardoso pergunta, a propósito da multiplicidade de tipos de autoritarismo na América Latina de fins dos anos 1970 e da eventual tentativa de situá-los todos sob o rótulo de burocrático-autoritários (Chile e México, além de Brasil, Argentina e Uruguai, mas também Peru, Panamá, Equador...), se o nível de abstração não seria

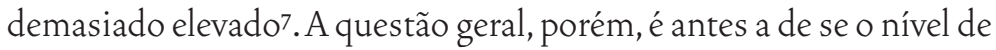
abstração não seria baixo diante das interrogações maiores envolvidas: será efetivamente possível dar conta de nossa experiência burocrático-autoritária, e mesmo da fluidez e dos vaivéns do processo que leva a ela e eventualmente a supera, sem uma perspectiva adequadamente ambiciosa no plano teórico e o resultante instrumental analítico apropriado ao trabalho empírico e comparativo?

$\mathrm{Na}$ obra de O'Donnell, a disposição a respeito dessa indagação comporta ambiguidades e hesitações. Num nível epistemológico mais básico, tal disposição chega a manifestar-se, em texto assinado por ele e Schmitter em Transições do regime autoritário ${ }^{8}$, num ceticismo radical quanto à própria possibilidade, em geral, de uma teoria da mudança, ou de apreender e processar cientificamente em termos de regularidades a "extraordinária incerteza" de processos de transição, "com suas inúmeras surpresas e difíceis dilemas". A teoria em questão é descrita como devendo ser uma "teoria da anormalidade", vista como paradoxal, ea "metodologia da ciência normal" é repudiada como inapropriadaa "situações de rápida mudança", o queincluiria o caso das transições a partir de regimes autoritários. Não admira, nessa perspectiva, que o diagnóstico inicial dos regimes BA e das condições de sua implantação tenha evoluído, na literatura da "transitologia" e da "consolidologia" (como Schmitter as rotulou jocosamente)9, para uma perseguição algo míope dos eventos, em que certa fenomenologia do colapso da democracia e da dinâmica autoritária (sem dúvida acompanhada, no caso de O'Donnell, de complexa visão das articulações entre aspectos relativos ao substrato socioeconômico e de enfrentamento de classes, seus desdobramentos organizacionais, sociopsicológicos e ideológicos, suas ramificações transnacionais etc. ${ }^{10}$ ) se faz seguir justamente pelo exame das "aberturas", depois das "transições" e enfim, de modo mais problemático, das "consolidações" democráticas.

Há, contudo, na história recente da ciência política, uma clara alternativa a essa perspectiva. Refiro-me aos trabalhos sobre o tema do desenvolvimento político que floresceram sobretudo nas décadas de 1960 e 70, caracterizados por ambição e ousadia teóricas e pela 
disposição de tomar como objeto de estudo sistemático, e em escala global, o processo de implantação e desenvolvimento do estado nacional moderno e as vicissitudes e resistências nele enfrentadas pela construção da democracia. Muito da literatura correspondente partia de pressupostos de nítido etnocentrismo anglo-saxônio ou estritamente estadunidense. A revisão crítica necessária, porém, não poderia pretender redundar no abandono da desinibição teórica e do alcance da reflexão sobre o processo de mudança política, em que o desafio é lidar com a fluidez mesma de tal processo, com vistas a apreender a sua lógica, e da qual uma "teoria dos autoritarismos modernos" seria parte natural. Infelizmente, esse abandono foi o que tendeu a acontecer, com o "desenvolvimento político" reduzido, com a ajuda de "transitólogos" e "consolidólogos", a moda passageira.

O’Donnell fez autocrítica explícita, num de seus escritos, quanto a suas próprias resistências à literatura do desenvolvimento político ${ }^{11}$. E creio que a parte mais importante do seu trabalho posterior pode ser lida como a retomada, afim àquela literatura, da ambição teórica relativamente à democracia e a seu desenvolvimento.

Um passo vacilante a respeito é o artigo "Democracia delegativa?" ${ }^{2}$. O'Donnell reconhece nele a inexistência, na ciência política, de uma teoria genética satisfatória das instituições, bem como de uma teoria da construção democrática ${ }^{13}$ — e tais teorias, que são na verdade uma só (ou que se relacionariam de forma que a segunda poderia vir a brotar da primeira), correspondem ao grande objetivo a ser perseguido pela disciplina quanto ao anseio democrático que constitui seu inevitável conteúdo normativo. Mas o reconhecimento dessa lacuna surge aos olhos de O'Donnell antes como justificativa para a "teorização" problemática (de relações equívocas com o objetivo de chegar parcimoniosamente à teoria das instituições) sobre um "novo animal", supostamente peculiar e duradouro, a ser encontrado em alguns países democraticamente deficientes. Não obstante tenhamos a apresentação das características a serem assumidas pelas instituições num "sistema institucional operativo", as deficiências envolvem a ideia de que não haveria, nas democracias delegativas, o enquadramento institucional adequado da interação estratégica entre os agentes sociopolíticos. Embora O’Donnell prefira falar de clientelismo, patrimonialismo e corrupção, descritos de passagem como "instituições, não formalizadas mas fortemente atuantes"14, trata-se claramente de um quadro de precariedade institucional afim ao que Samuel Huntington andou chamando de "pretorianismo", em que grupos e categorias variadas buscam seu interesse próprio num cenário de "vale tudo" que favorece, ao cabo, o protagonismo dos militares. Mas é então difícil perceber o que se ganha ao caracterizar as democracias delegativas como um tipo singular de democracia.
[11] Veja-se O'Donnell, G.Contrapontos: autoritarismo e democratização. São Paulo:Vértice, 1986, n.14, pp.152-53.

[12] O'Donnell, G. "Democracia delegativa?", Novos Estudos Cebrap, n.31, out.1991.

[13] Ibidem, p.30.

[14] Ibidem. 
[15] Ponhamos de lado o fato de que a confirmação empírica da existência difusa dessa disposição é problemática no caso do Brasil, uma das principais referências de O'Donnell a respeito e onde se aplicaram inicialmente perguntas de questionário cuja elaboração contou com sua participação direta, em projetos de pesquisa em que colaboramos, mencionados acima. Veja-se a discussão dos dados pertinentes em Reis, Fábio W e Castro, Mônica M. M. de. "Democracia, civismo e cinismo: um estudo empírico sobre normas e racionalidade", Revista Brasileira de Ciências Sociais, vol.16, n. 45, fev. 2001.

[16] Vejam-se, por exemplo, Linz, Juan Linz, "Presidencialismo ou parlamentarismo: faz alguma diferença?". In: Lamounier, Bolívar (org.). A opção parlamentarista. São Paulo: IDESP/ Sumaré, 1991; e Lijphart, Arend. "Presidencialismo e democracia majoritária". In: Ibidem.

[17] Veja-se O'Donnell, G. Contrapuntos: Ensayos Escogidos sobre Autoritarismo y Democratización. Buenos Aires: Paidós, 1997, cap. 11.
Significará isso que elas podem "consolidar-se" mesmo enquanto delegativas? Tal consolidação ocorreria com sua institucionalização apropriada? Ou a precariedade institucional é um dos aspectos definidores $\mathrm{da}$ democracia delegativa? O traço, aparentemente essencial, da existência de certo desinteresse quanto à participação, ou da disposição de delegar sem mais ao presidente ou chefe do governo a atribuição de governar como melhor lhe pareça $a^{15}$, faria talvez da democracia delegativa um pretorianismo de tipo especial. Mas note-se queessa disposição e os demais traços apresentados como característicos das democracias delegativas (o plebiscitarismo ou cesarismo e o chefe do governo visto como "encarnação da nação", o majoritarismo etc.) mostram-se amplamente coincidentes com os que autores como Juan Linz e Arend Lijphart apontaram comocaracterísticos do presidencialismo, mesmo nos Estados Unidos ${ }^{16}$. Ora, os Estados Unidos não são incluídos como exemplo de democracia delegativa, nem correspondem, certamente, a um caso de pretorianismo no sentido proposto por Huntington. Nem parece ser intenção de O'Donnell assimilar presidencialismo e democracia delegativa.

O'Donnell é mais afirmativo e avança na elaboração das mesmas questões em outro texto aparentado, "Otra Institucionalización"17. Falando aí não de democracias delegativas, mas de "novas democracias" ou "novas poliarquias", por contraste com as que se acham estabelecidas há muito no "quadrante noroeste do planeta", ele torna inequívoca, como sugere o título, a condição institucionalizada dos traços distintivos das novas democracias, com todas as suas precariedades. Ainda que lhes faltem as instituições formais efetivas das velhas democracias (vistas como casos de institucionalização "plena"), não lhes faltam instituições informais, e O'Donnell elabora bastante extensamente o caráter de instituições informais que se teria nas práticas particularistas e neopatrimonialistas (edelegativas...) - ou, diria eu, no conjunto de traços negativos em que a política tanto corrupta quanto pretoriana seenraíza.

Há aqui importante ambiguidade. De um lado,é sem dúvida correta a visão, que pode servinculada a Durkheim,em que os mecanismos sociais, em geral, ganham exterioridade em relação aos indivíduos e os coagem, o que resulta em padrões de comportamento e nas instituições informais de que fala O'Donnell — ou, ao cabo, em tradições ou culturas variadas. De outro lado, a contraposição do "formal" ao "informal" a propósito da institucionalização e da eventual consolidação da democracia, bem como a vinculação latente do "formal" com o politicamente bom ("plenamente" institucionalizado) e do "informal" com o precário e deficiente, omite algo fundamental quanto à natureza das instituições políticas, que seliga à face durkheimiana das instituições em geral: só há instituições políticas reais na medida em que seus "formalismos" lançam raízes no "informal", ou seja, na medida em que se integram em tradições ou culturas em que o agir de acordo com as normas se torne, em grau significativo, espontâneo 
ou natural. O problema está em obter que o "informal”, que está sempre presente, se torne o suporte de "boas" normas e de uma aparelhagem estatal (formal) apropriadamene democrática. Ea dificuldade principal envolvida, que se relaciona de maneira complicada com aspectos relativos à estrutura socioeconômica e ao inevitável jogo dos interesses a ser tido em conta com realismo, está nas incertezas sobre as relações de causalidade entre cultura e democracia, que há muito são motivo de polêmica na literatura de ciência política: é a cultura (política) adequada que produz a democracia ou cabe esperar que a experiência de viver sob a democracia, mesmo se deflagrada em condições por diferentes aspectos negativas ou pouco favoráveis, venha a produzir a cultura adequada? Um aspecto relevante do que aqui está em jogo diz respeito à articulação dos componentes estritamente normativos do processo de institucionalização democrática com seus componentes cognitivos, vale dizer, as percepções, crenças e expectativas que são parte decisiva do cálculo relacionado aos interesses e que podem ter grande importância no condicionamento da efetividade da operação das normas - mesmo das normas a que as pessoas de fato aderem. Isso nos põe em contato com a interseção e a tensão, nas explicações da implantação e da consolidação da democracia, entre a perspectiva que destaca o papel causal da cultura, dos valores e das normas, de um lado, e, de outro, a perspectiva "realista" que salienta nas instituições políticas, incluídas as democráticas, sua feição de "equilíbrio" e acomodação "automática" do jogo dos cálculos intencionais e estratégicos relativos aos interesses por definição particularistas ${ }^{18}$.

Seja como for, o que parece possível descrever como a caminhada de O'Donnell rumo a uma teoria ambiciosa do processo de desenvolvimento político culmina com o denso ensaio programático que divulgou em 1999, "Teoria democrática e política comparada"19. O objetivo explícito do ensaio é alcançar uma concepção de democracia não só consistente, mas também capaz de "viajar", ou seja, de aplicar-se a experimentos democráticos como os das "novas democracias", não plenamente consolidadas, tanto quanto às poliarquias tradicionais e estáveis dos países "originários". Esse objetivo o leva, contra "a tendência a-histórica e o foco estreito nos aspectos formais do regime encontrados em muitas teorias correntes da democracia", a uma ampla sociologia historicamente atenta da mudança política. Nela, a consideração dos aspectos relacionados à formação e à atuação do Estado e ao desenvolvimento do sistema legal racional-formal e da "aposta" democrática "temperada" pelo liberalismo se articula com a atenção para o substrato "civil" e informal da penetração da ideia dos direitos do indivíduo e de sua autonomia ("agency", a envolver a presunção de autonomia que acarreta responsabilidade), penetração esta que se acopla, de maneira complexa quanto às precedências envolvidas, à afirmação do próprio capitalismo - e que se desdobra, na outra ponta, nas exigências de afirmação dos direitos sociais e

\begin{abstract}
[18] Veja-se Reis e Castro, op. cit., para o exame dessas sugestões com referência a dados empíricos e a contribuições teóricas relevantes, em particular de Adam Przeworski.
\end{abstract}

[19] Cito o título da versão em português, publicada em Dados, vol. 42, n. 4, 1999. Uma versão digital em inglês foi divulgada em 2000 pelo Kellogg Institute, como Working Paper n. 274, sob o título "Democracy, Law, and Comparative Politics" (http://kellogg.nd.edu/publications/workingpapers/WPS/274.pdf). Este é também o título da versão publicada em Studies in Comparative International Development, vol. 36, n. 1, primavera 2001. $\mathrm{O}$ artigo, premiado pela Associação Americana de Ciência Política com o prêmio Luebbert, incorpora e expande ideias apresentadas em textos produzidos no período imediatamente anterior, incluídos "Horizontal Accountability and New Polyarchies". In: Schedler, A.; Diamond, L. e Plattner, M. F. (orgs.). The Self-Restraining State: Power and Accountability in New Democracies. Boulder/Londres: Lynne Rienner, 1999; e "Polyarchies and the (Un)Rule of Law in Latin America". In: Mendez, J.; O'Donnell, G. e Pinheiro, P. S. (orgs.). The Rule of Law and the Underprivileged in Latin America. Notre Dame: University of Notre Dame Press, 1999. Mas é ele mesmo uma espécie de versão preliminar do que viria a ser o último livro de Guillermo O'Donnell: na versão brasileira, O'Donnell, G.Democracia, Agência, Estado: teoria com intenção comparativa. São Paulo: Paz e Terra, 2011. 
[20] "Democracy, Law, and Comparative Politics", Kellogg Institute, pp. 47-48. Seria possível objetar a certa confusão conceitual nas relações entre "civil" e "político", cuja integração se afirma enquanto são separados conceitualmente; mas não há como opor-se à intuição da articulação entre as esferas relativas ao Estado è à sociedade, seja como for que se designem.

[21] Ibidem, p.47.

[22] Putnam, Robert. Making Democracy Work: Civic Traditions in Modern Italy. Princeton, NJ: Princeton University Press, 1993.

[23] Veja-se O’Donnell, G. “Transições, Continuidades e Alguns Paradoxos". In: Reis e O'Donnell, $A$ democracia no Brasil,op.cit. Observe-seque O'Donnell, reiterando a disposição ao exame crítico da própria obra que raramente se encontra, desautorizou posteriormente esse artigo (nota 2 de “Teoria Democrática e Política Comparada", nota 3 de "Democracy, Law, and Comparative Politics", Kellogg Institute), que compartilharia concepções relacionadas com consolidação democrática que ele mais tarde concluiu serem erradas. da construção legal do welfare state como parte importante das condições para a autonomia. As liberdades políticas, nota O'Donnell, "são parte integrante dos direitos civis; os sítios historicamente originários e mais frequentes de exercício de liberdades tais como as de expressão, crença religiosa, associação e ir e vir correspondem às transações cotidianas da sociedade, não à esfera da política", donde a conexão íntima da própria cidadania política com esse substrato civil ${ }^{20}$.

Essa integração benigna estaria presente nas democracias "originárias". Nas "novas democracias", porém, ainda que as eleições e a "aposta" democrática inclusiva nelas contida se tenham institucionalizado, teríamos "um tecido precário de direitos civis, tanto no plano territorial quanto no das classes e setores". Além disso, nos países correspondentes "muitas das salvaguardas liberais não se achavam em operação quando se adotou a aposta democrática, e em alguns deles ainda não se acham. Em consequência, os estratos privilegiados viram a extensão da aposta democrática como extremamente ameaçadora, com frequência recorrendo a uma dinâmica de repressão e exclusão - em confronto, no nível popular, com profunda alienação e eventualmente radicalização - que trouxeram dificuldades adicionais à expansão dos direitos de participação, políticos e civis"21.

Tal visão sociológica e teoricamente atrevida aponta, com certeza, o bom caminho. Continua a faltar, talvez, que se juntem de modo mais incisivo e frutífero o componente culturalista, que aí emerge nitidamente, e o componente "estratégico" referido ao jogo dos interesses, provavelmente mais capaz de propiciar respostas à pergunta de "que fazer?" ao mostrar-se mais passível de ser condicionado nos cálculos envolvidos. Pois a cultura e suas mudanças tendem a remeter ao longo prazo, e a um longo prazo que, em sua extensão, tende a tornar-se irrelevante para as urgências práticas em jogo - como Robert Putnam nos mostrava, não exatamente por querer, ao fazer remontar à Idade Média os fatores culturais propícios à operação efetiva da democracia em certas regiões da Itália contemporânea ${ }^{22}$.

Como quer que seja, é bem claro que a avaliação de O'Donnell das dificuldades das novas democracias se aplica amplamente ao Brasil. E cabe concluir com o rápido exame de sugestões de O'Donnell a respeito especificamente dos problemas da transição à democracia no Brasile dos prospectos de sua eventual consolidação, que aparecemem sua contribuição ao volume que editamos conjuntamente em $1988^{23}$. O foco é a ideia de "paradoxos do êxito", que se ajustaria ao caso brasileiro porque aqui, em contraste com outros casos (como, talvezespecialmente, a Argentina), teríamos tido um regime BA menos repressivo, além de economicamente dinâmico. O'Donnell alerta contra a adesão, sem mais, à premissa de que isso resultaria em melhores perspectivas de consolidação democrática, ressaltando algumas "desvantagens" a que estaríamos expostos: além da 
maior desigualdade e suas sequelas politicamente negativas, teríamos, por um lado, a memória "menos cerradamente negativa" do regime autoritário e, por outro, traços diversos que representariam continuidades com respeito a ele, tais como a manutenção da intensa presença no Estado de figuras políticas comprometidas com o autoritarismo e de grande peso das próprias forças armadas. Tudo isso aumentaria os riscos de recaída autoritária, ainda que talvez sob a forma de uma "morte lenta" da democracia, antes que de turbulência e novos golpes imediatos. Aderindo a um modelo "estratégico" em que a interação de atores menos ou mais democráticos assume papel importante, O'Donnell chegava mesmo a evocar como relevante, numa versão preliminar do texto, a preocupação de Max Weber quanto às possíveis consequências do desprestígio da classe política e do parlamento da Alemanha nos começos do século XX, preocupação vista como profética em relação à tragédia que mais tarde acometeu o país. E a sugestão é a de que o Brasil, pelos vários aspectos ligados ao que aparece como "êxito", correria o risco de algum tipo de desenlace trágico.

A referência a Weber e à tragédia alemã (mesmo excluída da versão final de um texto ele próprio desautorizado) permitelevar como que ao extremo certa lógica básica relativa à questão de análise e diagnóstico (realísticos...) versus "que fazer". Se confrontamos Brasil eArgentina, esta última, sem embargo de supostamente melhores perspectivas de consolidação democrática no momento em que escrevia O'Donnell, teve a sua própria tragédia (menor que a da Alemanha, maior que a nossa): a guerra suja, o medo, os cemitérios clandestinos. E o argumento acabaria encerrado numa espécie de círculo em que por um lado é preciso fazer democracia real para evitar tragédias, mas por outro a experiência de tragédias seria boa para que se possa fazer democracia real. Se pelo menos a segunda metade dessa proposição circular não comportasse dúvidas... Mas na verdade não está excluída a possibilidade de que uma tragédia menor acabe levando a tragédias maiores.

Há uma alternativa mais consistente e (talvez devesse dizer "apesar de") mais realista. Ela partiria de afirmar inequivocamente que é preciso evitar tragédias, e que não tem cabimento pretender apostar nos efeitos positivos de tragédias coletivas, em tragédias "pequenas" que criariam as condições para que o drama posterior assumisse a forma de um jogo civilizado, republicano e democrático. Isso permitiria ver com olhos mais favoráveis, ou ao menos mais tolerantes, a famosa tendência brasileira à "conciliação" (descrita por O'Donnell em termos da tendência à "coalizão de todos com todos") e a resiliência de muitos traços próprios da política oligárquica, que sem dúvida, em vez de corresponderem a mero "estilo" cultural, se ligam aos aspectos estruturais associados com o pesado legado do escravismo e com a desigualdade brasileira. Assim, em vez de um "êxito" autoritário que reduz as chances de consolidação democrática, o aspecto superficialmente paradoxal estaria antes em que o maior 
[24] Reis, F. W. "Consolidação democrática e construção do Estado: notas introdutórias e uma tese". In: Reis e O'Donnell, $A$ democracia no Brasil, op. cit.
Recebido para publicação em 16 de janeiro de 2012.

\section{NOVOS ESTUDOS}

CEBRAP

92, março 2012

pp. $143-151$ atraso social geral do Brasil, em confronto com países como a Argentina, favoreceria um avanço mais tranquilo - ainda que de imediato fatalmente menos igualitário - rumo a uma eventual institucionalização democrática estável. Em outras palavras, o que tenho chamado de "problema constitucional" (o problema de enquadrar institucionalmente de maneira efetiva a incorporação sociopolítica de todos, em particular dos estratos populares) se tem colocado no Brasil de forma menos aguda e dramática, como consequência da passividade herdada da estrutura de castas do escravismo e do ânimo popular menos reivindicante. E um aspecto crucial das turbulências brasileiras das últimas décadas tem a ver justamente com o agravamento do problema constitucional, diante da crescente mobilização social e seus desdobramentos na arena política isto é, com certa aproximação das condições da Argentina.

Tal perspectiva "realista" me parece afim à recomendação de tratar de agir diretamente no plano legal (das instituições "formais", que a perspectiva de O'Donnell sugere serem mais difíceis de moldar cabalmente), pondo provisoriamente de lado as viscosidades estruturais e culturais e procurando condicionar de modo propício as expectativas e o cálculo dos agentes. Meu próprio trabalho, em texto incluído no mesmo volume organizado em colaboração com O'Donnell ${ }^{24}$, fornece boa ilustração dos riscos envolvidos, com sugestões sobre como lidar com as forças armadas brasileiras que a história do pós-1985 mostra serem de um realismo excessivo e supérfluo, não obstante as dificuldades que subsistem nas relações de civis e militares entre nós e no processamento do lado mais sombrio da ditadura militar de 1964.

De todo modo, esse erro, em si mesmo, aponta para fatos positivos. Pois, com todos os senões estruturais e culturais, "formais" e "informais", levamos mais de um quarto de século de uma dinâmica em que avanços econômicos e sociais se mostraram possíveis e ditaduras militares, burocráticas ou não, vão se transformando cada vez mais em esquisitices de um passado que se afasta.É com certeza auspicioso que a paixão democrática de O'Donnell, em parte substancial desse quarto de século, o tenha levado a ocupar-se com particularismos, clientelismos e quejandos, e não com generais truculentos e tortura e morte.

Resta que possamos fazer sentido, de fato, do que se passou. Afinal, tivemos até a derrocada do socialismo e o fim da Guerra Fria, em que o substrato estrutural do nosso vaivém político viu romper-se seu demorado enquadramento internacional de decisiva relevância, e mesmo a respeito de um evento de tal alcance a perplexidade ainda é grande. A tarefa é difícil. Mas o legado do nosso saudoso Guillermo O’Donnell será certamente de ajuda.

FÁBIO WANDERLEY REIS é cientista político e professor emérito da Universidade Federal de Minas Gerais. 